\title{
Comment on An additional challenge of Lake Kivu in Central Africa-upward movement of the chemoclines by Finn Hirslund
}

\author{
Martin SCHMID, ${ }^{*}$ KellyAnn ROSS, Alfred WÜEST \\ Eawag: Swiss Federal Institute of Aquatic Science and Technology, Surface Waters - Research and Management, \\ Seestrasse 79, CH-6047 Kastanienbaum, Switzerland. \\ *Corresponding author: martin.schmid@eawag.ch
}

\begin{abstract}
In a paper published earlier this year, Finn Hirslund suggested to release degassed deepwater from methane harvesting to the surface layer of Lake Kivu in order to counteract an observed slow rising of the chemoclines in the lake. In this comment, we present strong evidence for the presence of subaquatic springs in the lake that maintain the chemoclines at their present levels. Furthermore, the observed changes in the stratification do not call for urgent action. We therefore strongly advise against the proposed measures, which would most probably be harmful for the ecosystem, and instead propose to further monitor the development of the stratification in the lake.
\end{abstract}

Key words: Lake Kivu, methane, subaquatic springs.

Received: January 2012. Accepted: March 2012.

\section{INTRODUCTION}

Lake Kivu is one of the large East African rift lakes. Its deepwater contains enormous amounts of dissolved methane $\left(\mathrm{CH}_{4}\right)$ and carbon dioxide $\left(\mathrm{CO}_{2}\right)$ (Tietze, 1978). These gases are a natural hazard, as they could potentially lead to a gas eruption from the lake if their concentrations increase further (Schmid et al., 2005). However, the dissolved $\mathrm{CH}^{4}$ can also be extracted from the lake and used for power production. Large-scale $\mathrm{CH}_{4}$ extraction is expected to be developed in the next few decades.

Hirslund (2012) analysed vertical profiles of conductivity measured in Lake Kivu between 1974 and 2009 by different authors (Degens et al., 1973; Tietze, 1978; Schmid et al., 2005; Umutoni et al., 2009). He showed that the centres of gravity of the three major density gradients (chemoclines) located at depths of $\sim 190 \mathrm{~m}$ (upper chemocline), $\sim 260 \mathrm{~m}$ (main chemocline), and $\sim 315 \mathrm{~m}$ (lower chemocline) have risen by 6 to $10 \mathrm{~m}$ within these 35 years. He concluded that the hypothesis of Schmid et al. (2005) that the gradients are maintained at their depths by subaquatic inflows must be wrong. He further proposed that the negative temperature peaks, which were regularly observed above the main gradient [e.g., Fig. 6 in Hirslund (2012)], are not caused by subaquatic inflows but by an overflow from a separate basin to the northwest of the lake (Kabuno Bay). He then extrapolated the rising of the chemoclines into the future and concluded that in 300 or more years a situation could be reached where at certain depths dissolved gases could accumulate to dangerous, but not economically extractable, concentrations. Finally, he suggested to use the methane extraction facil- ities to counteract the rising of the chemoclines by releasing $-0.25 \mathrm{~km}^{3} \mathrm{yr}^{-1}$ of degassed deepwater into the mixolimnion.

With this comment we intend to show that several of the main arguments brought forward by Hirslund (2012) cannot be supported by the available data. Furthermore, we strongly advise against the proposed measures because they could be deleterious to fisheries and the lake ecology, while there is no evidence for their necessity.

\section{Rising of chemoclines}

We agree with the observation by Hirslund (2012) that the centres of gravity of the chemoclines have risen between 1974 and present. However, a large amount of this rise is due to an uplift of the lower boundaries of the chemoclines, while their upper boundaries remained at almost the same depths. We aligned the vertical conductivity gradients from profiles measured in February 2004 (Schmid et al., 2005), and in January 2010 (measured with an RBR XR-620 CTD profiler), with those published in Fig. 7.2 of Tietze (1978). We are aware that this method is not ideal and that several possible error sources may influence the comparison as discussed further below, but as the raw data from Tietze (1978) is not available, it is the best possible approach.

The comparison shows that the lower boundaries of the three gradients moved upwards by 10 to $15 \mathrm{~m}$, while the upper boundaries remained at almost the same depths. The chemoclines therefore became thinner by these 10 to $15 \mathrm{~m}$, which explains most of the rise of the centres of gravity observed by Hirslund (2012). Vertical microstruc- 
ture temperature profiles measured by Newman (1976) in 1972 confirm that the chemoclines were thicker in the early 1970s. The sharpening of the chemoclines is a strong argument against the hypothesis of Hirslund (2012) that the chemoclines are simply pushed upwards in the water column. Hirslund (2012) also argued that the assumption that the gradients are maintained by a combination of upwelling water and subaquatic inflows at certain depths must be wrong because the gradients are symmetrical. However, this statement is not correct. Especially in 1974/1975 when Tietze (1978) made his measurements, the gradients were far from symmetrical, and the main chemocline had a much sharper upper than lower boundary (Fig. 1). The gradients became more symmetrical since then because they became steeper.

While the upper boundaries of the upper and lower gradients did not change visibly in Fig. 1, the upper boundary of the main chemocline may have risen by $\sim 3$ to $4 \mathrm{~m}$ from 1974 to 2010 . However, this difference is hardly larger than the range of error that may have been introduced by the following error sources: i) digitizing the plot from Tietze (1978) is accurate within $\sim 2 \mathrm{~m}$; ii) the depths of the chemoclines vary with distance from the subaquatic inflows and with time due to internal waves. For our measurements from 2004 and 2010, the depth variation between different profiles from the same year is $\sim 1 \mathrm{~m}$ for the main chemocline and up to $5 \mathrm{~m}$ for the upper chemocline; iii) the depth determinations by the different pressure sensors, and slight differences in the conversion from pressure to depth may create errors of $\sim 0.5$ to $1.0 \mathrm{~m}$; iv) the lake level varies by $\sim 0.5 \mathrm{~m}$ due to variations in precipitation and hydropower production (Pasche, 2012). Nevertheless, a comparison of CTD profiles measured at similar locations between 2002 (Lorke et al., 2004) and 2011 seems also to indicate a slight upward movement of the main chemocline.

The reason for the rise of the lower boundaries of the chemoclines has not yet been definitively determined. The simplest explanation is to assume that the structure of the stratification is only due to hydrothermal sources in the deepwater, upwelling, diffusion and the cool lateral inflows at the top of the gradients. Then the rise of the lower boundary of a chemocline and the steepening of the gradient could be explained by an increase of the integrated discharge of the springs below this chemocline. Such an intensification of the subaquatic spring discharge would be in agreement with relatively high precipitation since the 1960s and an observed warming below the main chemocline where most of the springs are warmer than the ambient lake water (Schmid and Wüest, 2012; Pasche, 2012). Other potential mechanisms for sharpening the lower boundary of a chemocline would be convective mixing of a large layer or the formation or intensification of warm inflows directly below the chemocline. However, especially for the convective mixing it would be surprising if this had happened simultaneously for all three chemoclines in the last 30 years.

\section{Cool inflows}

Hirslund (2012) denies the existence of cool inflows that maintain the temperature gradients at their current depths. The quality of evidence is different for each of the three gradient layers, and we therefore discuss them separately in the following section.

The clearest case is the main chemocline. Negative temperature peaks just above this chemocline have been observed in many temperature profiles taken near the northern shore of Lake Kivu. Fig. 2 shows the intensity of these negative peaks for 55 temperature profiles measured on 16 to 21 January 2010 in the main basin of Lake Kivu. The signal is clearly strongest near a point on the steep northern flank of the lake, south of the City of Goma and becomes weaker with distance from this point in all directions, particularly in the direction of Kabuno Bay. One of the profiles with the strongest peaks is shown in Fig. 3. This is very convincing evidence that these negative temperature peaks are caused by a local spring (or a set of local springs) entering the lake at this location, disproving the idea that it is an overflow of dense water from Kabuno Bay as proposed by Hirslund (2012). Furthermore, the cool inflows have a lower conductivity than the lake water at the same depth, whereas an overflow from Kabuno Bay would have a higher conductivity. The water from Kabuno Bay, at the depth where it has a density of

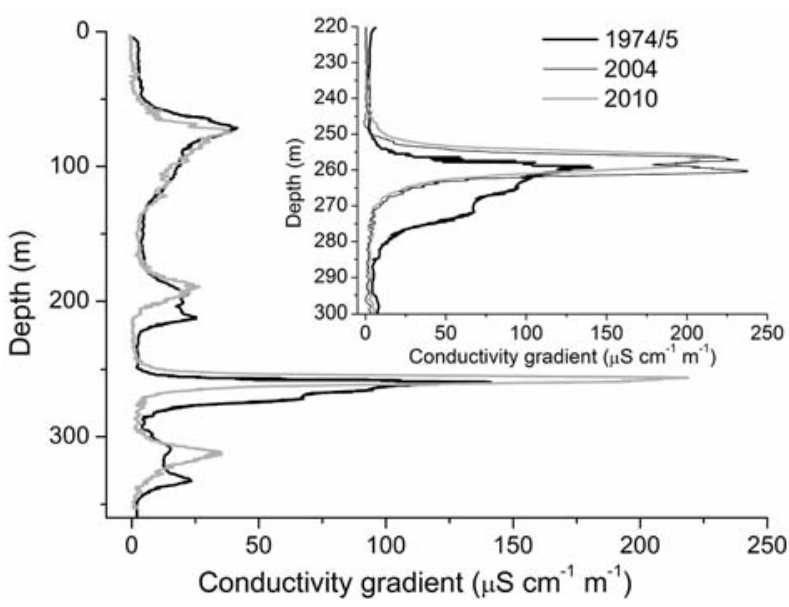

Fig. 1. Vertical gradients of in situ conductivity in Lake Kivu. Thick black line: average of 23 profiles measured by Tietze (1978) between 14 November 1974 and 20 January 1975, digitized from Tietze (1978); thick grey line: average of 12 profiles measured between 11 and 16 January 2010; thin black line (only in the inset): average of 4 profiles measured between 17 and 21 February 2004. 
$1000.7 \mathrm{~kg} \mathrm{~m}^{-3}$ as proposed by Hirslund (2012), has a conductivity of $3700 \mu \mathrm{S} \mathrm{cm} \mathrm{cm}^{-1}$ compared to $3150 \mu \mathrm{S} \mathrm{cm}^{-1}$ in the nearly-mixed layer above the main gradient. In January 2012, the overflowing water from Kabuno Bay has been tracked by CTD profiling in the north-western part of the lake and has been observed to stratify at the base of the mixolimnion, at 40 to $60 \mathrm{~m}$ depth.

Furthermore, Hirslund (2012) argues that it is not possible that a spring with a temperature as low as 22 to $23^{\circ} \mathrm{C}$ could enter the lake at a depth of $250 \mathrm{~m}$, because the groundwater temperature should be significantly higher than the lake surface temperature at this depth. However, the mean annual air temperature at Lake Kivu is $\sim 19$ to $20^{\circ} \mathrm{C}$ (Sarmento et al., 2006) and therefore several degrees cooler than the lake surface temperature. The temperature of shallow groundwater is usually near the mean annual air temperature. The global borehole database (Pollack et al., 1998) at the National Climatic Data Center (NCDC) does not include measurements from nearby Lake Kivu, but temperature differences between $20 \mathrm{~m}$ and $250 \mathrm{~m}$ depth for other locations in East Africa range between 2.5 and $3.5^{\circ} \mathrm{C}$. A groundwater spring temperature of $\sim 23^{\circ} \mathrm{C}$ at $250 \mathrm{~m}$ depth, as proposed by Schmid et al. (2005) and as observed in the measurements, is therefore in perfect agreement with typical vertical geothermal gradients in East Africa.

We acknowledge that the available data is not sufficient to prove that the spring is effectively entering the lake at $\sim 250 \mathrm{~m}$ depth. It is also possible that the spring water is entering nearby at a slightly higher level and that the cooler water then flows down the slope and entrains ambient lake water before it stratifies at the top of the gradient. However, the opposing case would not be possible. If the spring would enter the lake at a level significantly below the gradient, it would entrain enough ambient water while rising through the gradient to draw the gradient back down to the level of entrance of the spring. Because upwelling tends to push the whole stratification upwards, the natural steady-state level for the gradient layers is just below the depth of entrance of the subaquatic cool springs. Since the present stratification in the lake must have developed over the last thousand or more years (Schmid et al., 2005), it is very probable that the gradient layers have adjusted to these natural levels.

For the two other chemoclines, we also observed clear signals of cold inflows at the top of the gradients, even though they were less prominent than for the main chemocline. Recent observations (Fig. 3) show that the cold inflows at the top of the upper chemocline do not enter the lake as a strong point source, but as numerous smaller sources of groundwater between 80 and $190 \mathrm{~m}$ depth. Nevertheless, the strongest negative temperature deviations from the background profiles were observed between $140 \mathrm{~m}$ and $190 \mathrm{~m}$ depth, at locations close to those

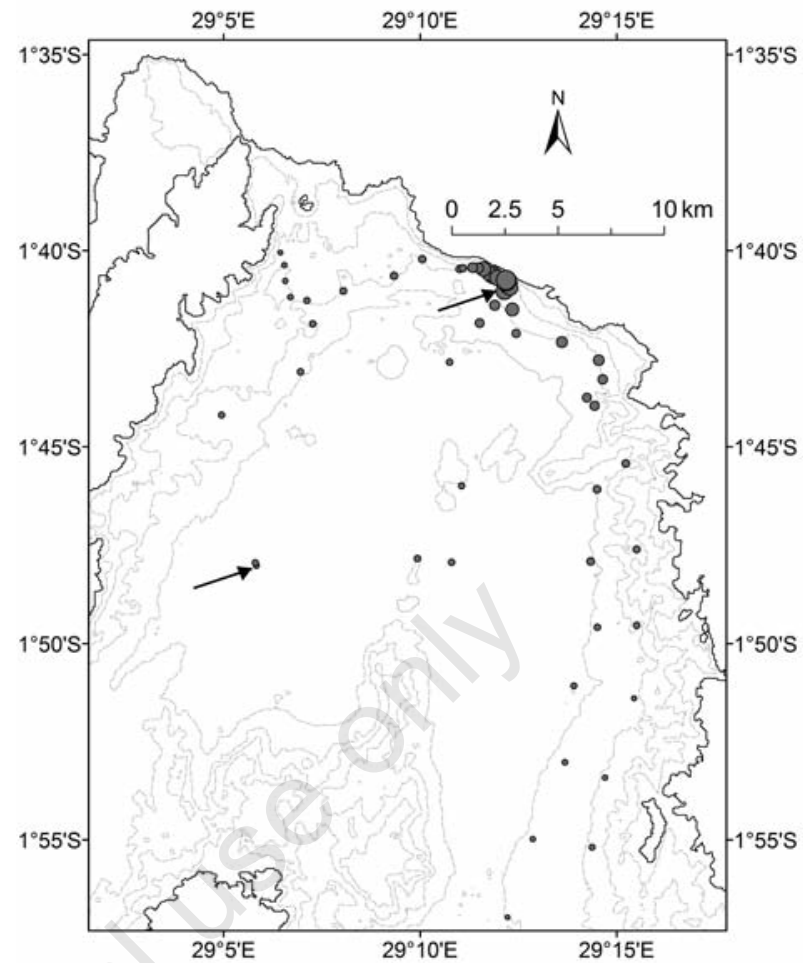

Fig. 2. Map of the northern part of Lake Kivu. The circles indicate the positions where CTD profiles reaching below $250 \mathrm{~m}$ depth were taken in January 2010. The circle sizes indicate the difference between $24^{\circ} \mathrm{C}$ and the minimum temperature between 240 and $270 \mathrm{~m}$ depth for each profile (range between $0.045^{\circ} \mathrm{C}$ and $0.72^{\circ} \mathrm{C}$, corresponding to minimum temperatures of $23.955^{\circ} \mathrm{C}$ and $23.28^{\circ} \mathrm{C}$, respectively). The two arrows mark the locations of the two profiles shown in Fig. 3. The dashed grey lines indicate depth intervals of $100 \mathrm{~m}$.

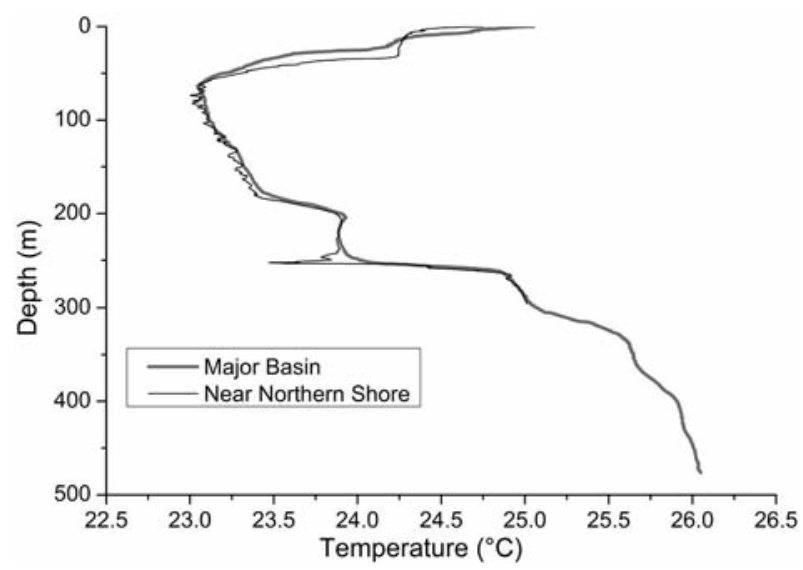

Fig. 3. Comparison of temperature profiles measured in the centre of the main basin and near the northern shore of Lake Kivu on 16 and 19 January 2010. The positions of the profiles are marked with arrows in Fig. 2. 
where the strongest peaks were detected between 240 and $270 \mathrm{~m}$ depth (Fig. 2). Several profiles measured in the north-eastern part of the lake in January 2012 show weak negative temperature peaks between 290 and $310 \mathrm{~m}$ depth, just above the lower chemocline. Based on the model predictions (Schmid et al., 2005), the discharge of the inflow at this depth is by a factor of $\sim 20$ smaller than the inflows above the upper and the main chemocline, so it is not surprising that the signal of this spring is more difficult to detect.

The time scale for horizontal mixing is on the order of one year or less, while the upwelling rate ranges between 0.15 and $0.9 \mathrm{~m} \mathrm{yr}^{-1}$ (Schmid and Wüest, 2012). The dilution of the upwelling water with the water from the subaquatic springs that occurs in one part of the lake is therefore sufficiently quickly redistributed to the entire lake to keep the chemoclines within less than $1 \mathrm{~m}$ at their depths in the entire lake.

In summary, we agree that the centres of gravity of the chemoclines have risen by a few meters in the last 35 years. However, this rise is mainly due to a rise of the lower boundaries of the chemoclines, while the upper boundaries remained almost at their depths. Since the two boundaries are not rising at the same rate, there must be an active process that prevents the upper boundaries from rising. There is strong evidence that this process is the inflow of subaquatic springs providing cool and fresh water to the top of the gradients. For the main chemocline, the source location of this subaquatic spring has been determined by field measurements.

\section{Conclusions for the management of the lake}

Hirslund (2012) concludes that the rise of the chemoclines may, in a time scale of 300 years or more, lead to a situation where dissolved gases could accumulate to dangerous but not economically extractable concentrations at relatively shallow depths. He therefore suggests that a significant fraction $\left(\sim 0.25 \mathrm{~km}^{3} \mathrm{yr}^{-1}\right)$ of the degassed water from the $\mathrm{CH}_{4}$ extraction facilities should be released to the mixolimnion in order to counteract the upward movement of the gradients. We strongly advise against such a measure for the following reasons:

The deepwater of Lake Kivu contains enormously high nutrient concentrations (up to $0.18 \mathrm{mmol} \mathrm{L}^{-1}$ dissolved inorganic phosphorus and $4 \mathrm{mmol} \mathrm{L}^{-1}$ ammonium; Pasche et al., 2009) and also high concentrations of reduced substances. As mentioned by Hirslund (2012), the suggested measure would increase the phosphorus fluxes to the surface layer by almost $40 \%$, leading to higher primary production and subsequently higher oxygen consumption in the lower part of the mixolimnion. Oxygen would be further depleted by the oxidation of reduced substances contained in the deepwater. The proposed addition of nutrients and reduced substances would thus fur- ther increase the anoxic volume that develops already today in the lower part of the mixolimnion during the stratified period. Very low oxygen concentrations could subsequently be reached in the whole mixolimnion during the onset of mixing at the beginning of the dry season. It should also be mentioned that discharging water with these properties to the surface layer of a lake would be against environmental legislation in most developed countries. These countries have spent enormous amounts of money in the last decades in order to achieve the opposite, i.e., to reduce nutrient inputs to lakes and to avoid the negative impacts of eutrophication. Even though the areal fish production of Lake Kivu is lower than that of other East African lakes, the yield of $\sim 10,000 \mathrm{t}$ fish per year from the lake (Snoeks et al., 2012) is an important local protein source. We therefore think that very strong arguments are required to propose such a measure that would be forbidden by environmental legislations in industrialized countries and may be deleterious to the ecology and fisheries. It would be irresponsible to discharge degassed deepwater to the surface layer of Lake Kivu without clear proof that it is required in order to avoid a dangerous situation.

Furthermore, even according to the estimates of Hirslund (2012) a dangerous situation would only be expected to occur in 300 years or more from now. There is ample time to investigate whether the threat is real and any measures are required. We therefore propose to monitor the further development of the chemoclines for the next decades. Such a monitoring is foreseen in the Management Prescriptions for gas extraction from Lake Kivu (Boyle et al., 2009) and is already implemented by the Government of Rwanda. This will result in a valuable and consistent database that should allow predicting the future development of the chemoclines with more confidence than today. Even if the chemoclines should indeed rise at the rates suggested by Hirslund (2012), they would in 30 years have been lifted by only $\leq 10 \mathrm{~m}$. This would have no relevant impact on the safety of the lake. This time should be used for further studies on the inflow depths, locations and discharge of subaquatic springs in the lake, as well as the characteristics of the ecosystem and its vulnerability to nutrient additions. Should the monitoring indicate that, in the long term, action against the rising of the chemoclines must be taken, then enough information should be available to do this with as little negative impact on the ecosystem as possible.

\section{REFERENCES}

Boyle J, Hirslund F, Morkel P, Schmid M, Tietze K, Wüest A, 2009. Management prescriptions for the development of Lake Kivu gas resources. Document prepared for the Ministry of Infrastructure, Rwanda and the Ministry of Hydrocarbons, D.R. Congo.

Degens ET, von Herzen RP, Wong HK, Deuser WG, Jannasch 
HW, 1973. Lake Kivu: Structure, chemistry and biology of an East African Rift Lake. Geol. Rundsch. 62:245-277.

Hirslund F, 2012. An additional challenge of Lake Kivu in Central Africa - upward movement of the chemoclines. J. Limnol. 71:45-60.

Lorke A, Tietze K, Halbwachs M, Wüest A, 2004. Response of Lake Kivu stratification to lava inflow and climate warming. Limnol. Oceanogr. 49:778-783.

Newman FC, 1976. Temperature steps in Lake Kivu: a bottom heated saline lake. J. Phys. Oceanogr. 6:157-163.

Pasche N, 2012. Paleolimnology of Lake Kivu: past climate and recent environmental changes, p. 153-163. In: J.P. Descy, F. Darchambeau and M. Schmid (eds.) Lake Kivu: Limnology and biogeochemistry of a tropical great lake. Springer, Dordrecht, The Netherlands.

Pasche N, Dinkel C, Müller B, Schmid M, Wüest A, Wehrli B, 2009. Physical and biogeochemical limits to internal nutrient loading of meromictic Lake Kivu. Limnol. Oceanogr. 54:1863-1873.

Pollack HN, Huang S, Shen PY, 1998. Climate change record in subsurface temperatures: A global perspective. Science 282:279-281.

Sarmento H, Isumbisho M, Descy JP, 2006. Phytoplankton ecology of Lake Kivu (eastern Africa). J. Plankton Res. 28:815829.
Schmid M, Halbwachs M, Wehrli B, Wüest A, 2005. Weak mixing in Lake Kivu: new insights indicate increasing risk of uncontrolled gas eruption. Geochem. Geophy. Geosy. 6:Q07009.

Schmid M, Busbridge M, Wüest A, 2010. Double-diffusive convection in Lake Kivu. Limnol. Oceanogr. 55:225-238.

Schmid M, Wüest A, 2012. Stratification, mixing and transport processes in Lake Kivu, p. 13-29. In: J.P. Descy, F. Darchambeau and M. Schmid (eds.) Lake Kivu: Limnology and biogeochemistry of a unique tropical lake. Springer, Dordrecht, The Netherlands.

Snoeks J, Kaningini B, Masilya P, Nyina-wamwiza L, Guillard J, 2012. Fishes in Lake Kivu: diversity and fisheries, p. 127152. In: J.P. Descy, F. Darchambeau and M. Schmid (eds.) Lake Kivu: Limnology and biogeochemistry of a unique tropical lake. Springer, Dordrecht, The Netherlands.

Tietze K, 1978. Geophysikalische Untersuchung des Kivusees und seiner ungewöhnlichen Methangaslagerstätte - Schichtung, Dynamik und Gasgehalt des Seewassers. PhD Thesis, Christian-Albrechts-Universität Kiel, Germany.

Umutoni A, Mugisha A, Nzayisenga T, Rwandekwe L, 2009. Baseline survey at REC concession site prior to the settlement of the platform on the $10^{\text {th }}$ of June 2009. Monitoring report. Ministry of Infrastructure, Kigali, Rwanda. 